\title{
Clinical characteristics and outcomes of critically ill patients with COVID-19 in Kobe, Japan: a single-center, retrospective, observational study
}

\author{
Jiro Ito ${ }^{1}$ - Ryutaro Seo ${ }^{2} \cdot$ Daisuke Kawakami $^{1} \cdot$ Yoshinori Matsuoka ${ }^{2} \cdot$ Kenjiro Ouchi $^{1} \cdot$ Suguru Nonami ${ }^{1}$. \\ Yusuke Miyoshi ${ }^{1} \cdot$ Masao Tatebe $^{1} \cdot$ Takahiro Tsuchida $^{1} \cdot$ Yoko Asaka $^{2} \cdot$ Machi Yanai $^{2} \cdot$ Hiroshi Ueta $^{1}$.

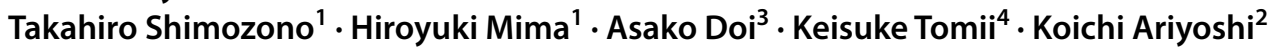

Received: 2 August 2020 / Accepted: 8 January 2021 / Published online: 23 January 2021

(c) Japanese Society of Anesthesiologists 2021

\begin{abstract}
Purpose Coronavirus disease 2019 (COVID-19) has placed a great burden on critical care services worldwide. Data regarding critically ill COVID-19 patients and their demand of critical care services outside of initial COVID-19 epicenters are lacking. This study described clinical characteristics and outcomes of critically ill COVID-19 patients and the capacity of a COVID-19-dedicated intensive care unit (ICU) in Kobe, Japan.

Methods This retrospective observational study included critically ill COVID-19 patients admitted to a 14-bed COVID19-dedicated ICU in Kobe between March 3, 2020 and June 21, 2020. Clinical and daily ICU occupancy data were obtained from electrical medical records. The last follow-up day was June 28, 2020.

Results Of 32 patients included, the median hospital follow-up period was 27 (interquartile range 19-50) days. The median age was 68 (57-76) years; 23 (72\%) were men and 25 (78\%) had at least one comorbidity. Nineteen (59\%) patients received invasive mechanical ventilation for a median duration of 14 (8-27) days. Until all patients were discharged from the ICU on June 5, 2020, the median daily ICU occupancy was 50\% (36-71\%). As of June 28, 2020, six (19\%) died during hospitalization. Of $26(81 \%)$ survivors, 23 (72\%) were discharged from the hospital and three (9\%) remained in the hospital.

Conclusion During the first months of the outbreak in Kobe, most critically ill patients were men aged $\geq 60$ years with at least one comorbidity and on mechanical ventilation; the ICU capacity was not strained, and the case-fatality rate was $19 \%$.
\end{abstract}

Keywords Coronavirus $\cdot$ Severe acute respiratory syndrome coronavirus $2 \cdot$ Critical care $\cdot$ Mortality $\cdot$ Respiration, artificial $\cdot$ Respiratory distress syndrome, adult $\cdot$ Bed occupancy

Supplementary Information The online version contains supplementary material available at https://doi.org/10.1007/s0054 0-021-02897-w.

Jiro Ito

phyandeth69boo@gmail.com

1 Department of Anesthesia and Critical Care, Kobe City Medical Center General Hospital, 2-1-1, Minatojima-minamimachi, Chuo-ku, Kobe, Hyogo 650-0047, Japan

2 Department of Emergency Medicine, Kobe City Medical Center General Hospital, Kobe, Hyogo, Japan

3 Department of Infectious Diseases, Kobe City Medical Center General Hospital, Kobe, Hyogo, Japan

4 Department of Respiratory Medicine, Kobe City Medical Center General Hospital, Kobe, Hyogo, Japan

\section{Introduction}

Coronavirus disease 2019 (COVID-19), caused by severe acute respiratory syndrome coronavirus 2 (SARS-CoV-2), has spread globally. As of June 21, 2020, there have been 17,864 confirmed cases of COVID-19 with 953 deaths in Japan [1]. In Kobe, which is located in West Japan with a population of approximately 1.5 million, there have been 285 confirmed cases and 12 deaths [2].

Previous studies from Wuhan in China, the first COVID19 epicenter, reported significant increases in demand for critical care services, and the case-fatality rate ranged from 39 to $62 \%$ in critically ill patients [3-5]. Outside of the epicenters, however, insufficient data on the clinical course of critically ill patients with COVID-19 and their strain on the critical care capacity exist. The objective of the present study 
was to describe the clinical characteristics and outcomes of critically ill patients with COVID-19 and the capacity of a COVID-19-dedicated intensive care unit (ICU) in Kobe during the first months of the city's outbreak.

\section{Methods}

\section{Study design}

This single-center, retrospective, observational study was conducted at the Kobe City Medical Center General Hospital (KCGH), a 760-bed tertiary referral center providing emergency medical care to approximately 35,000 patients per year in Kobe.

Since the first case of COVID-19 in Kobe on March 3, 2020, the city's surge capacity strategies were implemented as follows. Critically ill patients with COVID-19 were preferentially admitted or transferred to $\mathrm{KCGH}$, while noncritically ill patients with COVID-19 and non-COVID-19 patients were admitted to the surrounding hospitals in Kobe. Pre-existing medical and cardiac ICUs at KCGH were combined into the COVID-19-dedicated ICU with 14 beds and ventilators; 24/7 intensivists and intensive care nurses with a nurse:patient ratio of 1:1 were staffed by deploying them from medical, cardiac, and surgical ICUs. Non-COVID-19 patients who had been admitted to the ICUs before March 3, 2020, were scheduled for transfer to the surgical ICU or stepdown wards in the hospital. Non-urgent elective surgeries were rescheduled to maintain ICU capacity for both COVID19 and non-COVID-19 patients. A pre-existing 32-bed stepdown ward was used for COVID-19 patients discharged from the ICU. COVID-19 protocols, which were based on the World Health Organization (WHO) interim guidance [6] and/or relevant evidence for management of critically ill patients, were prepared (Supplemental Material 1: p2).

\section{Study population}

This study included critically ill patients with laboratoryconfirmed COVID-19 admitted to the COVID-19-dedicated ICU at KCGH between March 3, 2020 and June 21, 2020. Laboratory confirmation of COVID-19 was based on the detection of SARS-CoV-2 RNA using reverse transcriptasepolymerase chain reaction (RT-PCR) analysis of a nasopharyngeal swab specimen in accordance with the Centers for Disease Control and Prevention guidelines [6]. Data on the number of COVID-19 patients in Kobe during the study period were also obtained from the Kobe city official COVID-19 control site [2]. Our local Institutional Review Board approved the study (approval number: Zn200518) and waived the need for written informed consent.
Predetermined ICU admission criteria for COVID-19 patients included (1) the need for immediate intubation, (2) mechanical ventilation, (3) deteriorating respiratory status requiring $\geq 5 \mathrm{~L} / \mathrm{min}$ supplemental oxygenation to meet a peripheral capillary oxygen saturation $\left(\mathrm{SpO}_{2}\right)$ of $\geq 90 \%$, (4) shock, (5) acute organ dysfunction, or (6) need for close monitoring as judged by treating physicians. Critically ill patients were defined according to the WHO interim guidance [7], which included patients with acute respiratory distress syndrome (ARDS) $[8,9]$ or sepsis with acute organ dysfunction [10].

\section{Data collection}

Using electronic medical records, we reviewed data on age, sex, body-mass index (BMI), smoking history, comorbidities, onset of symptoms, do-not-intubate (DNI) orders, presenting symptoms, hospital admission route, laboratory tests, imaging tests, microbiological tests, and patient management in the ICU. Chest computed tomography (CT) images were independently reviewed by two intensivists with approximately 5 years of experience (JI and DK). Lung laterality, presence of ground glass opacity (GGO) or consolidation, distribution pattern (peripheral, multifocal, central, diffuse), and other findings were recorded. The final decisions reached by consensus are reported. We calculated the Acute Physiology and Chronic Health Evaluation II (APACHE II) scores, Sequential Organ Failure Assessment (SOFA) scores, and the partial pressure of arterial oxygen $\left(\mathrm{PaO}_{2}\right)$ to the fraction of inspired oxygen $\left(\mathrm{FiO}_{2}\right)$ ratios during ICU stay to assess disease severity $[8,11$, 12]. We calculated daily ICU occupancy as the percentage of beds in use out of the total number of beds available for each day at midnight to assess ICU capacity $[13,14]$. The clinical outcomes included ICU deaths, in-hospital deaths, dispositions of the survivors, length of ICU and hospital stays, duration of invasive mechanical ventilation, complications documented during ICU stay, and time from symptom onset to negative RT-PCR. The last follow-up day was June 28, 2020.

\section{Statistical analysis}

No statistical sample size calculation was performed a priori owing to the nature of the study. Continuous variables are presented as medians (interquartile range). Categorical variables are presented as $n(\%)$. All data were analyzed using JMP 11 (SAS Institute, Cary, NC, USA).

\section{Results}

Between March 3, 2020 and June 21, 2020, of 285 patients with laboratory-confirmed COVID-19 in Kobe, 189 (66\%), including two with critical illness, were treated in other 
hospitals. Ninety-six (34\%) patients were admitted to KCGH, of whom 32 (11\%) with critical illness admitted to the ICU were included (Fig. 1). The median hospital followup period was 27 (19-50) days. All patients were Japanese adults with a median age of $68(57-76)$ years; $23(72 \%)$ were men (Table 1). The median BMI obtained from 23 patients was $24.8(22.9-27.2) \mathrm{kg} / \mathrm{m}^{2}$. Twenty-five (78\%) patients had at least one comorbidity: the most common comorbidities were hypertension (19 [59\%]) and diabetes (8 [25\%]). Four (13\%) patients had DNI orders. The most common presenting symptoms were fever (29 [91\%]), dyspnea (20 [63\%]), cough (19 [59\%]), fatigue (17 [53\%]), and anorexia (9 [28\%]). The median duration from onset of symptoms to hospital admission and ICU admission was 7 (4-9) days and 8 (5-10) days, respectively. Twelve (38\%) patients were admitted through the emergency department at KCGH; 18 $(56 \%)$ transferred from surrounding hospitals, and two (6\%) were considered to be infected during the course of hospitalization at KCGH for acute illnesses other than COVID-19.

All patients were admitted to the ICU because of respiratory failure and met the criteria for both ARDS and sepsis at the time of ICU admission (Table 2). The median APACHE II and SOFA scores during the first $24 \mathrm{~h}$ after ICU admission were 17 (13-21) and 6 (3-7), respectively. The median $\mathrm{PaO}_{2} / \mathrm{FiO}_{2}$ ratio on ICU admission, obtained from 31 patients, was 150 (115-172). The most common laboratory abnormalities on ICU admission were lymphocytopenia and elevated concentrations of aspartate aminotransferase and C-reactive protein. Chest CT images prior to ICU admission were obtained from 29 patients, with a median duration from symptom onset to CT scan of 6 (4-8) days. Bilateral lung involvement was observed in 28 patients (97\%). GGO and consolidation were observed in 29 (100\%) and 20 (69\%) patients, respectively. Common distribution patterns were peripheral (25 [86\%]) and multifocal (19 [66\%]). None of the patients with coinfection with influenza or mycoplasma were identified. Sputum samples were obtained from 18 patients, from which microorganisms including Staphylococcus aureus $(n=6)$, Streptococcus pneumoniae $(n=1)$, Klebsiella pneumoniae $(n=1)$, and Enterobacter cloacae complex $(n=1)$ were identified in nine patients. Blood samples were obtained from all patients, with Escherichia coli identified in one patient. During the ICU stay, 13 (41\%) patients received only supplemental oxygen without high-flow nasal cannula and non-invasive ventilation. One patient was treated with non-invasive ventilation prior to endotracheal intubation. Three patients were intubated at other hospitals before being transferred to KCGH; six at the emergency department, and 10 at the ICU. Thus, 19 patients $(59 \%)$ received invasive mechanical ventilation, of whom 13 received neuromuscular blockade, four were placed in the prone position, and none met the predetermined criteria for the initiation of venovenous extracorporeal membrane oxygenation (Table 3). The lowest $\mathrm{PaO}_{2} / \mathrm{FiO}_{2}$ ratio during the first three days of invasive mechanical ventilation was 119 (106-142).

Fourteen (44\%) patients presented with hypotension requiring vasoconstrictive agents for $\geq 6 \mathrm{~h}$ and 11 (34\%) hypertensive patients were treated with antihypertensive agents. Seventeen $(53 \%)$ patients were treated with diuretics and seven (22\%) with renal replacement therapy. All 19 mechanically ventilated patients received enteral nutrition and one also received parenteral nutrition; the remaining 13 non-intubated patients received only oral nutrition. Prophylaxis for stress ulcers and venous thromboembolism was administered in $24(75 \%)$ and $32(100 \%)$ patients, respectively. Nine (28\%) patients also received therapeutic anticoagulation with intravenous unfractionated heparin for at least one of the following indications: atrial fibrillation
Fig. 1 Study flow diagram. COVID-19 coronavirus disease 2019, KCGH Kobe City Medical Center General Hospital, $I C U$ intensive care unit. During the study period, critically ill patients with COVID-19 in Kobe were preferentially admitted or transferred to KCGH
285 patients with confirmed COVID-19 in Kobe, Japan between Mar 3, 2020 and June 21, 2020

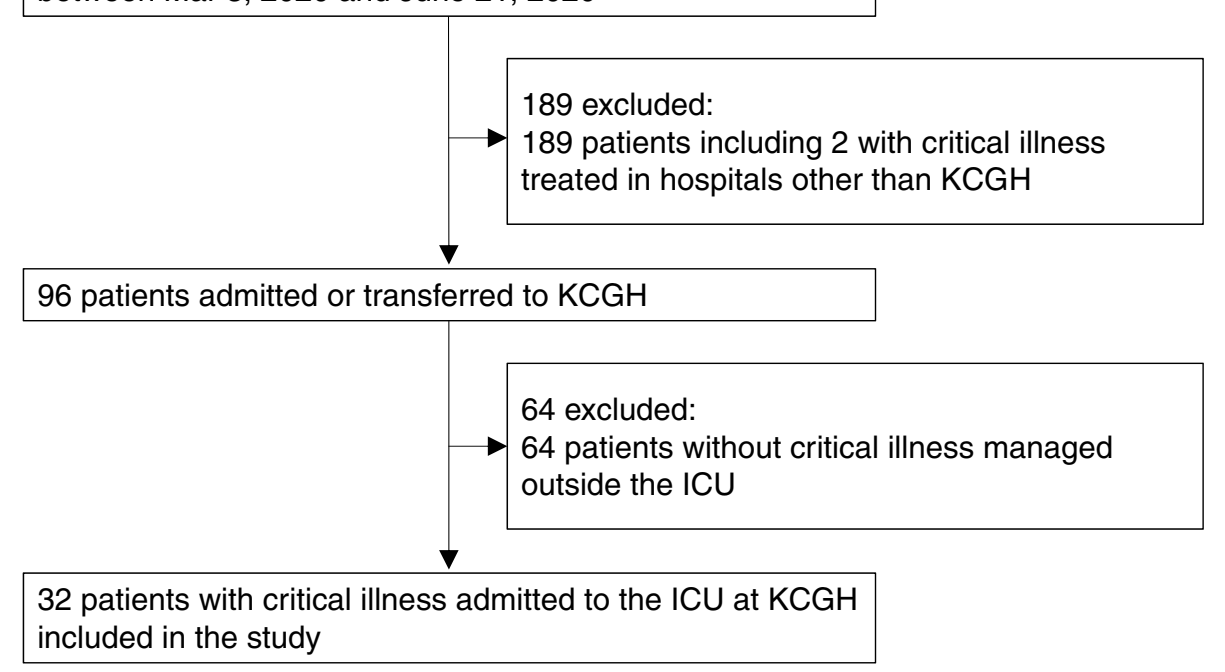


Table 1 Demographics and presenting symptoms of study population

\begin{tabular}{|c|c|}
\hline & Study population $(n=32)$ \\
\hline Japanese & $32(100)$ \\
\hline Age, years & $68(57-76)$ \\
\hline $30-39$ & $1(3)$ \\
\hline $40-49$ & $4(13)$ \\
\hline $50-59$ & $5(16)$ \\
\hline $60-69$ & $7(22)$ \\
\hline $70-79$ & $9(28)$ \\
\hline $80-89$ & $6(19)$ \\
\hline \multicolumn{2}{|l|}{ Sex } \\
\hline Female & $9(28)$ \\
\hline Male & $23(72)$ \\
\hline Body-mass index, $\mathrm{kg} / \mathrm{m}^{2}$ & $24.8(22.9-27.2)$ \\
\hline$\leq 18.4$ & $1(3)$ \\
\hline $18.5-24.9$ & $12(38)$ \\
\hline $25.0-29.9$ & $8(25)$ \\
\hline $30.0-34.9$ & $2(6)$ \\
\hline Unknown & $9(28)$ \\
\hline Current or former smoker, no./total no. $(\%)^{\mathrm{a}}$ & $11 / 31(42)$ \\
\hline \multicolumn{2}{|l|}{ Comorbidities } \\
\hline None & $7(22)$ \\
\hline Hypertension & $19(59)$ \\
\hline Diabetes & $8(25)$ \\
\hline Cardiovascular disease $^{\mathrm{b}}$ & $6(19)$ \\
\hline Chronic kidney disease & $5(16)$ \\
\hline Hemodialysis & $2(6)$ \\
\hline Chronic lung disease ${ }^{c}$ & $2(6)$ \\
\hline Malignancy & $1(3)$ \\
\hline Immunodeficiency & $1(3)$ \\
\hline Chronic liver disease & 0 \\
\hline Do-not-intubate order & $4(13)$ \\
\hline Duration from onset of symptoms to hospital admission, days ${ }^{\mathrm{d}}$ & $7(4-9)$ \\
\hline Duration from onset of symptoms to ICU admission, days ${ }^{\mathrm{d}}$ & $8(5-10)$ \\
\hline \multicolumn{2}{|l|}{ Symptoms } \\
\hline Fever $^{\mathrm{e}}$ & $29(91)$ \\
\hline Dyspnea & $20(63)$ \\
\hline Cough & $19(59)$ \\
\hline Fatigue & $17(53)$ \\
\hline Anorexia & $9(28)$ \\
\hline Diarrhea & $5(16)$ \\
\hline Myalgias & $2(6)$ \\
\hline Olfactory and taste disorders & $2(6)$ \\
\hline Arthralgia & $1(3)$ \\
\hline Sore throat & $1(3)$ \\
\hline \multicolumn{2}{|l|}{ Hospital admission route of patients } \\
\hline Admission through emergency department & $12(38)$ \\
\hline Transferred from other hospital & $18(56)$ \\
\hline Others ${ }^{\mathrm{f}}$ & $2(6)$ \\
\hline
\end{tabular}

Data are presented as number (\%) or median (interquartile range) unless otherwise noted COVID-19 coronavirus disease 2019, ICU intensive care unit

${ }^{\mathrm{a} D}$ Data available for 31 patients

${ }^{\mathrm{b}}$ Coronary artery disease or heart failure

${ }^{\mathrm{c}}$ Asthma or interstitial lung disease

${ }^{\mathrm{d}}$ Data available for 27 patients

${ }^{\mathrm{e}} \mathrm{S}$ elf-reported history of temperature $\geq 37.5^{\circ} \mathrm{C}$ or feeling feverish

${ }^{\mathrm{f}}$ Two patients considered to be infected during hospitalization 
Table 2 Clinical characteristics of study population on ICU admission

\begin{tabular}{|c|c|}
\hline Characteristics & Study population $(\mathrm{n}=32)$ \\
\hline ARDS & $32(100)$ \\
\hline Sepsis & $32(100)$ \\
\hline Septic shock & $1(3)$ \\
\hline APACHE II score during first $24 \mathrm{~h}$ after ICU admission & $17(13-21)$ \\
\hline SOFA score during first $24 \mathrm{~h}$ after ICU admission & $6(3-7)$ \\
\hline $\mathrm{PaO}_{2} / \mathrm{FiO}_{2}$ ratio on ICU admission ${ }^{\mathrm{a}}$ & $150(115-172)$ \\
\hline Lowest $\mathrm{PaO}_{2} / \mathrm{FiO}_{2}$ ratio during first $3 \mathrm{ICU}$ days ${ }^{\mathrm{a}}$ & $127(74-159)$ \\
\hline \multicolumn{2}{|l|}{ Laboratory tests } \\
\hline White blood cell count, $\times 10^{9} / \mathrm{L}$ & $6.6(4.9-9.0)$ \\
\hline Lymphocyte count, $\times 10^{9} / \mathrm{L}^{\mathrm{b}}$ & $0.6(0.5-0.9)$ \\
\hline Platelet, $\times 10^{9} / \mathrm{L}$ & $170(145-252)$ \\
\hline Aspartate aminotransferase, U/L & $52(36-93)$ \\
\hline Alanine aminotransferase, $\mathrm{U} / \mathrm{L}$ & $27(18-40)$ \\
\hline Creatinine, $\mathrm{mg} / \mathrm{dL}$ & $0.84(0.64-1.16)$ \\
\hline C-reactive protein, $\mathrm{mg} / \mathrm{dL}$ & $13.1(8.6-18.7)$ \\
\hline \multicolumn{2}{|l|}{ Chest CT findings, no. positive/total no. $(\%)^{\mathrm{c}}$} \\
\hline Ground glass opacity & $29 / 29(100)$ \\
\hline Consolidation & $20 / 29(69)$ \\
\hline Bilateral involvement & $28 / 29(97)$ \\
\hline Peripheral distribution & $25 / 29(86)$ \\
\hline Multifocal distribution & $19 / 29(66)$ \\
\hline Diffuse distribution & $10 / 29(34)$ \\
\hline \multicolumn{2}{|l|}{ Microbiology tests, no. positive/total no. (\%) } \\
\hline Influenza A/B & $0 / 21$ \\
\hline Mycoplasma & $0 / 19$ \\
\hline Sputum culture $^{\mathrm{d}}$ & $9 / 18(50)$ \\
\hline Blood culture ${ }^{\mathrm{e}}$ & $1 / 32(3)$ \\
\hline
\end{tabular}

Data are presented as number (\%) or median (interquartile range) unless otherwise noted

ICU intensive care unit, COVID-19 coronavirus disease 2019, APACHE II Acute Physiology and Chronic Health Evaluation II, SOFA Sequential Organ Failure Assessment score, ARDS acute respiratory distress syndrome, $\mathrm{PaO}_{2}$ the partial pressure of arterial oxygen, $\mathrm{F}_{i} \mathrm{O}_{2}$ the fraction of inspired oxygen, $\mathrm{CT}$ computed tomography

${ }^{\text {a }}$ Data available for 31 patients

${ }^{\mathrm{b}}$ Data available for 30 patients

${ }^{\mathrm{c}}$ Chest CT images prior to ICU admission obtained from 29 patients

${ }^{\mathrm{d}}$ Microorganisms identified from sputum cultures included Staphylococcus aureus $(n=6)$, Streptococcus pneumoniae $(n=1)$, Klebsiella pneumoniae $(n=1)$, and Enterobacter cloacae complex $(n=1)$

${ }^{\mathrm{e}}$ Escherichia coli was identified $(n=8)$, renal replacement therapy $(n=6)$, or venous thromboembolism $(n=1)$. Regarding pharmacotherapies, 30 (94\%) patients received empiric antibiotics; 27 (84\%), compassionate-use favipiravir; six (19\%), ciclesonide, and six (19\%), systemic glucocorticoids. Other antiviral agents or immunosuppressive agents were not used.

Until all patients included in the study were discharged from the ICU on June 5, 2020, the median daily ICU occupancy was 50\% (36-71\%) (Supplemental Material 1: Fig. S1). As of June 28, 2020, six (19\%) patients died in the hospital with a median duration from ICU admission of
14 (6-23) days; five (16\%) including two with DNI orders died in the ICU and one (3\%) with a DNI order died in the stepdown ward after ICU discharge (Table 4). Of the 19 mechanically ventilated patients, three (16\%) died in the ICU. The causes of death were cardiac failure $(n=3)$, respiratory failure $(n=2)$, and septic shock $(n=1)$. The detailed characteristics and clinical course of the six deceased patients are presented in Table S1 (Supplemental Material 1). Of 26 surviving patients, 23 discharged from the hospital and three had been discharged from the ICU but remained in the hospital. The median length of ICU 
Table 3 ICU management of patients with COVID-19

\begin{tabular}{|c|c|}
\hline & $\begin{array}{l}\text { Study } \\
\text { population } \\
(n=32)\end{array}$ \\
\hline \multicolumn{2}{|l|}{ Respiratory support } \\
\hline High-flow nasal cannula oxygen therapy & $0 / 32$ \\
\hline Non-invasive ventilation $^{\mathrm{a}}$ & $1 / 32(3)$ \\
\hline Invasive mechanical ventilation & $19 / 32(59)$ \\
\hline Neuromuscular blockade & $13 / 19(68)$ \\
\hline Prone position & $4 / 19(21)$ \\
\hline Extracorporeal membrane oxygenation ${ }^{\mathrm{b}}$ & $0 / 19$ \\
\hline Vasoconstrictive agents & $14 / 32(44)$ \\
\hline Inotropic agents & $0 / 32$ \\
\hline Antihypertensive agents & $11 / 32(34)$ \\
\hline Diuretics & $17 / 32(53)$ \\
\hline Renal replacement therapy & $7 / 32(22)$ \\
\hline Enteral nutrition $^{c}$ & $19 / 32(59)$ \\
\hline Parenteral nutrition $^{c}$ & $1 / 32(3)$ \\
\hline Stress ulcer prophylaxis & $24 / 32(75)$ \\
\hline Venous thromboembolism prophylaxis & $32 / 32(100)$ \\
\hline Therapeutic anticoagulation $^{\mathrm{d}}$ & $9 / 32(28)$ \\
\hline Atrial fibrillation & $8 / 9(89)$ \\
\hline Renal replacement therapy & $6 / 9(67)$ \\
\hline Venous thromboembolism & $1 / 9(11)$ \\
\hline \multicolumn{2}{|l|}{ Other pharmacotherapies } \\
\hline Empiric antibiotics & $30 / 32(94)$ \\
\hline Favipiravir & $27 / 32(84)$ \\
\hline Ciclesonide & $6 / 32(19)$ \\
\hline Glucocorticoids & $6 / 32(19)$ \\
\hline
\end{tabular}

Data are presented as number/total number $(\%)$ or median (interquartile range)

ICU intensive care unit, COVID-19 coronavirus disease 2019

${ }^{a}$ One patient treated with noninvasive ventilation prior to endotracheal intubation

${ }^{\mathrm{b}}$ The predetermined criteria for the initiation of VV-ECMO included a ratio of partial pressure of arterial oxygen $\left(\mathrm{PaO}_{2}\right)$ to the fraction of inspired oxygen $\left(\mathrm{FiO}_{2}\right)$ of $<50 \mathrm{~mm} \mathrm{Hg}$ for $>3 \mathrm{~h}$, a $\mathrm{PaO}_{2} / \mathrm{FiO}_{2}$ ratio of $<80 \mathrm{mmHg}$ for $>6 \mathrm{~h}$, or an arterial blood $\mathrm{pH}$ of $<7.25$ with a partial pressure of arterial carbon dioxide of $>60 \mathrm{mmHg}$ for $>6 \mathrm{~h}$, with a respiratory rate increase to 35 breaths per minute

${ }^{\mathrm{c}}$ Nineteen mechanically ventilated patients received enteral nutrition and one also received parenteral nutrition

${ }^{\mathrm{d}}$ Nine patients received therapeutic doses of unfractionated heparin intravenously for at least one indication, including atrial fibrillation, renal replacement therapy, and venous thrombosis

and hospital stay was 10 (4-19) days and 31 (24-55) days, respectively. The median duration of mechanical ventilation was 14 (8-27) days. Tracheostomy was performed in two patients who were free from mechanical ventilation at ICU discharge. The most common complications during ICU stay were hospital-acquired infections (15 [47\%]), acute hepatic injury (14 [44\%]), impaired consciousness (14 [44\%]), and
Table 4 Clinical outcomes of patients with COVID-19 admitted to ICU

\begin{tabular}{ll}
\hline & $\begin{array}{l}\text { Study } \\
\text { population } \\
(n=32)\end{array}$ \\
\hline ICU deaths $^{\text {In-hospital deaths }}{ }^{\mathrm{a}}$ & $5 / 32(16)$ \\
Still in ICU & $6 / 32(19)$ \\
Discharged from ICU but still in hospital & $0 / 32$ \\
Discharged from hospital & $3 / 32(9)$ \\
Duration of ICU stay, days & $23 / 32(72)$ \\
Survivors & $10(4-19)$ \\
Non-survivors & $9(4-16)$ \\
Duration of hospital stay, days & $14(6-23)$ \\
Survivors & $31(24-55)$ \\
$\quad$ Non-survivors & $31(26-65)$ \\
Duration of invasive mechanical ventilation, days & $28(8-46)$ \\
Survivors & $14(8-27)$ \\
$\quad$ Non-survivors & $12(7-27)$ \\
Tracheostomy & $25(20-36)$ \\
\hline
\end{tabular}

Data are presented as number/total number $(\%)$ or median (interquartile range). The last follow-up day was June 28, 2020

COVID-19 coronavirus disease $2019, I C U$ intensive care unit

${ }^{\text {a }}$ Three mechanically ventilated patients and three with do-not intubate orders

acute kidney injury (13 out of 30 patients without chronic hemodialysis [43\%]) (Supplemental Material 1: Table S2). The patients diagnosed with hospital-acquired infections included 10 with ventilator-associated pneumonia, two with Clostridioides difficile infections, one with a blood stream infection, and seven treated with broad-spectrum antibiotics for suspected sepsis or septic shock. For 25 of 26 survivors, the SARS-CoV-2 RT-PCR test was performed twice with a 24-h interval at 4 weeks after symptom onset according to our institutional protocol. Thirteen patients (52\%) had negative results on the first set of tests, while the remaining 12 patients required a median of 38 (IQR 32-43) days from symptom onset to achieve two consecutive negative RT-PCR results.

\section{Discussion}

In this study, we have described the clinical characteristics and outcomes of 32 critically ill patients with COVID-19 and the ICU occupancy in Kobe during the first months of the city's outbreak. Most patients were men aged $\geq 60$ years having normal weight and at least one comorbidity and required invasive mechanical ventilation. The median ICU occupancy was $50 \%$ and the case-fatality rate was as low as $19 \%$. 
The strength of this study is that we included almost all critically ill patients with COVID-19 admitted to ICUs in the city with a population of 1.5 million and followed all patients at least until ICU discharge. The detailed information about the study population and the ICU capacity during the outbreak will enable policy-makers outside the COVID19 epicenters to determine the potential need for increasing ICU capacity to prepare for a future influx of critically ill patients with COVID-19.

The demographic data of our cohort were generally consistent with those of the critically ill population in China [3-5, 15], the United States [16-19], Italy [20], and Canada [21], with the exception of patient ethnicity and BMI. The median BMI obtained in our cohort was lower than that available in data from the United States $\left(30-33 \mathrm{~kg} / \mathrm{m}^{2}\right)$ [17-19] and Canada $\left(28 \mathrm{~kg} / \mathrm{m}^{2}\right)$ [21].

The measures of disease severity of our cohort regarding APACHE II scores, SOFA scores, and $\mathrm{PaO}_{2} / \mathrm{FiO}_{2}$ ratios on ICU admission were also comparable to those in the aforementioned cohorts; the median APACHE II score available from three studies was $12.5-18$ [3, 16, 21]; the median SOFA score from six studies was 4-11 [3, 4, 15, 18, 19, 21] and the median $\mathrm{PaO}_{2} / \mathrm{FiO}_{2}$ on ICU admission from seven studies was 129-183 [15-21].

Although the patient management noted in the study was mainly usual critical care, COVID-19-specific pharmacotherapies, including favipiravir and ciclesonide, which were not used in the aforementioned studies [3-5, 15-21], were also administered as part of a registry study in Japan [22].

The case-fatality rate of critically ill patients with COVID-19 admitted to ICUs in our cohort was lower than that in the initial epicenters of COVID-19, including mainland China, the United States, and Italy (26-67\%) [3-5, 16-20]. Given that the baseline characteristics including age, the prevalence of comorbidities, and disease severity which are risk factors associated with death in critically ill patients with COVID-19 [3, 5, 20], are similar, it is reasonable to explore other factors affecting the case-fatality rate. Recently, two large cohort studies of in-hospital patients with COVID-19 in New York City [23] and the United Kingdom [24] reported that obesity was associated with critical illness and mortality. However, another study focusing on critically ill patients with COVID-19 in New York City did not observe any association between obesity and mortality [18]. In addition, the risk factors for critical illness and death should be considered separately, as a paradoxical association referred to as the obesity paradox has been reported between obesity and increased survival in patients with critical illness without COVID-19 [25, 26]. Thus, the effect of BMI on mortality in critically ill patients with COVID-19 is controversial and requires further investigation. To date, preliminary data are limited regarding the efficacy of the antiviral agents used in this study, favipiravir and ciclesonide, while their effect on mortality in critically ill patients with COVID-19 remains investigational [22, 27, 28].

Strain on ICU capacity is another potential factor affecting the mortality of critically ill patients with COVID-19, as shown in a previous study in the United States including patients with various diseases in 155 ICUs [14]. In the initial epicenters, despite their efforts to expand ICU capacity, a sharp surge in number of patients with COVID-19 in the short term caused a shortage of ICU beds, ventilators, and staff to care for critically ill patients [3, 29, 30]. In this study, the median daily ICU occupancy was as low as $50 \%$, which is explained by the low incidence of critically ill patients in Kobe and the city's surge strategies in advance, that included increasing the ICU beds with ventilators and well-trained ICU staff, and collaboration between neighboring hospitals. Outside the epicenters, studies from Hong Kong [15] and Vancouver [21] also reported retained adequate ICU capacity to care for critically ill patients with COVID-19 and their case-fatality rate of $12 \%$ and $15 \%$, respectively. The impact of regional ICU capacity on mortality of COVID-19 patients should be assessed using a nationwide study adjusting for other predisposing factors for mortality.

This study has several limitations. First, owing to the retrospective study design, we could not obtain complete data on baseline characteristics, laboratory abnormalities, and complications. Second, because of our focus on critically ill patients and the urgent timeline, our sample size was small. Finally, because of the short follow-up period, the case-fatality rate was likely to be underestimated and data on long-term outcomes are lacking.

\section{Conclusion}

Among the 32 critically ill patients with laboratory-confirmed COVID-19 admitted to the ICU, the majority were men aged $\geq 60$ years having normal weight and at least one comorbidity and required invasive mechanical ventilation. During the first months of the outbreak, the ICU capacity was not strained, and the case-fatality rate was $19 \%$.

Author contributions JI, RS, DK, and YM conceptualized the study. JI, DK, KO, SN, YM, MT, and TT contributed to data collection. JI performed data cleaning and statistical analysis, produced the figure, and drafted the manuscript. All authors revised the manuscript for important intellectual content and approved the final version of the manuscript.

Data availability The datasets used and/or analyzed during the current study are available from the corresponding author on reasonable request. 


\section{Compliance with ethical standards}

Conflict of interest The authors declare that they have no conflicts of interest.

\section{References}

1. Ministry of Health, Labour and Welfare. About coronavirus disease 2019 (COVID-19). https://www.mhlw.go.jp/stf/newpa ge_11621.html. Accessed 21 June 2020.

2. City of Kobe. Coronavirus disease situation report for Kobe city (as of 12:00, April 30 2020). https://www.city.kobe.lg.jp/a7357 6/kenko/health/infection/protection/covid_19.html. Accessed 21 June 2020.

3. Yang X, Yu Y, Xu J, Shu H, Xia J, Liu H, Wu Y, Zhang L, Yu Z, Fang M, Yu T, Wang Y, Pan S, Zou X, Yuan S, Shang Y. Clinical course and outcomes of critically ill patients with SARS-CoV-2 pneumonia in Wuhan, China: a single-centered, retrospective, observational study. Lancet Respir Med. 2020;8:475-81.

4. Yu Y, Xu D, Fu S, Zhang J, Yang X, Xu L, Xu J, Wu Y, Huang C, Ouyang Y, Yang L, Fang M, Xiao H, Ma J, Zhu W, Hu S, Hu Q, Ding D, Hu M, Zhu G, Xu W, Guo J, Xu J, Yuan H, Zhang B, Yu Z, Chen D, Yuan S, Shang Y. Patients with COVID-19 in 19 ICUs in Wuhan, China: a cross-sectional study. Crit Care. 2020;24:219.

5. Wang Y, Lu X, Li Y, Chen H, Chen T, Su N, Zhou J, Zhang B, Yan F, Wang J. Clinical course and outcomes of 344 intensive care patients with COVID-19. Am J Respir Crit Care Med. 2020;201:1430-4.

6. World Health Organization. Interim guidelines for collecting, handling, and testing clinical specimens from persons for coronavirus disease 2019 (COVID-19). https://www.cdc.gov/coronaviru s/2019-nCoV/lab/guidelines-clinical-specimens.html. Accessed 1 June 2020.

7. World Health Organizaion. Clinical management of severe acute respiratory infection (SARI) when COVID-19 disease is suspected: interim guidance. March 13, 2020. https://apps.who.int/ iris/bitstream/handle/10665/331446/WHO-2019-nCoV-clinical2020.4-eng.pdf?sequence $=1 \&$ is Allowed $=y$. Accessed 28 June 2020.

8. Force ADT, Ranieri VM, Rubenfeld GD, Thompson BT, Ferguson ND, Caldwell E, Fan E, Camporota L, Slutsky AS. Acute respiratory distress syndrome: the Berlin definition. JAMA. 2012;307:2526-33.

9. Riviello ED, Kiviri W, Twagirumugabe T, Mueller A, BannerGoodspeed VM, Officer L, Novack V, Mutumwinka M, Talmor DS, Fowler RA. Hospital incidence and outcomes of the acute respiratory distress syndrome using the Kigali modification of the Berlin definition. Am J Respir Crit Care Med. 2016;193:52-9.

10. Seymour CW, Liu VX, Iwashyna TJ, Brunkhorst FM, Rea TD, Scherag A, Rubenfeld G, Kahn JM, Shankar-Hari M, Singer M, Deutschman CS, Escobar GJ, Angus DC. Assessment of clinical criteria for sepsis: for the third international consensus definitions for sepsis and septic shock (sepsis-3). JAMA. 2016;315:762-74.

11. Knaus WA, Draper EA, Wagner DP, Zimmerman JE. APACHE II: a severity of disease classification system. Crit Care Med. 1985;13:818-29.

12. Vincent JL, Moreno R, Takala J, Willatts S, De Mendonca A, Bruining H, Reinhart CK, Suter PM, Thijs LG, The SOFA (Sepsis-related Organ Failure Assessment) score to describe organ dysfunction/failure. On behalf of the Working Group on SepsisRelated Problems of the European Society of Intensive Care Medicine. Intensive Care Med. 1996;22:707-10.
13. Kerlin MP, Harhay MO, Vranas KC, Cooney E, Ratcliffe SJ, Halpern SD. Objective factors associated with physicians' and nurses' perceptions of intensive care unit capacity strain. Ann Am Thorac Soc. 2014;11:167-72.

14. Gabler NB, Ratcliffe SJ, Wagner J, Asch DA, Rubenfeld GD, Angus DC, Halpern SD. Mortality among patients admitted to strained intensive care units. Am J Respir Crit Care Med. 2013;188:800-6.

15. Ling L, So C, Shum HP, Chan PKS, Lai CKC, Kandamby DH, Ho E, So D, Yan WW, Lui G, Leung WS, Chan MC, Gomersall CD. Critically ill patients with COVID-19 in Hong Kong: a multicentre retrospective observational cohort study. Crit Care Resusc. 2020;22:119-25.

16. Arentz M, Yim E, Klaff L, Lokhandwala S, Riedo FX, Chong M, Lee M. Characteristics and outcomes of 21 critically ill patients with COVID-19 in Washington state. JAMA. 2020;323:1612-4.

17. Bhatraju PK, Ghassemieh BJ, Nichols M, Kim R, Jerome KR, Nalla AK, Greninger AL, Pipavath S, Wurfel MM, Evans L, Kritek PA, West TE, Luks A, Gerbino A, Dale CR, Goldman JD, O'Mahony S, Mikacenic C. Covid-19 in critically ill patients in the Seattle region—case series. N Engl J Med. 2020;382:2012-22.

18. Cummings MJ, Baldwin MR, Abrams D, Jacobson SD, Meyer BJ, Balough EM, Aaron JG, Claassen J, Rabbani LE, Hastie J, Hochman BR, Salazar-Schicchi J, Yip NH, Brodie D, O'Donnell MR. Epidemiology, clinical course, and outcomes of critically ill adults with COVID-19 in New York City: a prospective cohort study. Lancet. 2020;395:1763-70.

19. Auld SC, Caridi-Scheible M, Blum JM, Robichaux C, Kraft C, Jacob JT, Jabaley CS, Carpenter D, Kaplow R, HernandezRomieu AC, Adelman MW, Martin GS, Coopersmith CM, Murphy DJ. Emory COVID-19 Quality and Clinical Research Collaborative. ICU and ventilator mortality among critically ill adults with coronavirus disease 2019. Crit Care Med. 2020;5:6. https:// doi.org/10.1097/CCM.0000000000004457.

20. Grasselli G, Zangrillo A, Zanella A, Antonelli M, Cabrini L, Castelli A, Cereda D, Coluccello A, Foti G, Fumagalli R, Iotti G, Latronico N, Lorini L, Merler S, Natalini G, Piatti A, Ranieri MV, Scandroglio AM, Storti E, Cecconi M, Pesenti A. COVID-19 Lombardy ICU Network. Baseline characteristics and outcomes of 1591 patients infected with SARS-CoV-2 admitted to ICUs of the Lombardy region, Italy. JAMA. 2020;323:1574-81.

21. Mitra AR, Fergusson NA, Lloyd-Smith E, Wormsbecker A, Foster D, Karpov A, Crowe S, Haljan G, Chittock DR, Kanji HD, Sekhon MS, Griesdale DEG. Baseline characteristics and outcomes of patients with COVID-19 admitted to intensive care units in Vancouver, Canada: a case series. CMAJ. 2020;192:E694-701.

22. COVID-19 REGISTRY JAPAN. https://covid-registry.ncgm.go.jp. Accessed 1 June 2020.

23. Petrilli CM, Jones SA, Yang J, Rajagopalan H, O'Donnell L, Chernyak Y, Tobin KA, Cerfolio RJ, Francois F, Horwitz LI. Factors associated with hospital admission and critical illness among 5279 people with coronavirus disease 2019 in New York City: prospective cohort study. BMJ. 2020;369:m1966.

24. Docherty AB, Harrison EM, Green CA, Hardwick HE, Pius R, Norman L, Holden KA, Read JM, Dondelinger F, Carson G, Merson L, Lee J, Plotkin D, Sigfrid L, Halpin S, Jackson C, Gamble C, Horby PW, Nguyen-Van-Tam JS, Ho A, Russell CD, Dunning J, Openshaw PJ, Baillie JK, Semple MG. ISARIC4C investigators. Features of 20133 UK patients in hospital with covid-19 using the ISARIC WHO Clinical Characterisation Protocol: prospective observational cohort study. BMJ. 2020;369:m1985.

25. Hogue CW Jr, Stearns JD, Colantuoni E, Robinson KA, Stierer T, Mitter N, Pronovost PJ, Needham DM. The impact of obesity on outcomes after critical illness: a meta-analysis. Intensive Care Med. 2009;35:1152-70. 
26. Zhi G, Xin W, Ying W, Guohong X, Shuying L. "Obesity Paradox" in Acute respiratory distress syndrome: a systematic review and meta-analysis. PLoS ONE. 2016;11:e0163677.

27. Cai Q, Yang M, Liu D, Chen J, Shu D, Xia J, Liao X, Gu Y, Cai Q, Yang Y, Shen C, Li X, Peng L, Huang D, Zhang J, Zhang S, Wang F, Liu J, Chen L, Chen S, Wang Z, Zhang Z, Cao R, Zhong W, Liu Y, Liu L. Experimental treatment with favipiravir for COVID-19: an open-label control study. Engineering (Beijing). 2020. https:// doi.org/10.1016/j.eng.2020.03.007.

28. Iwabuchi K, Yoshie K, Kurakami Y, Takahashi K, Kato Y, Morishima T. Therapeutic potential of ciclesonide inahalation for COVID-19 pneumonia: report of three cases. J Infect Chemother. 2020;26:625-32.
29. Griffin KM, Karas MG, Ivascu NS, Lief L. Hospital preparedness for COVID-19: a practical guide from a critical care perspective. Am J Respir Crit Care Med. 2020;201:1337-44.

30. Fagiuoli S, Lorini FL, Remuzzi G. Covid-19 Bergamo Hospital Crisis U. Adaptations and lessons in the province of Bergamo. $\mathrm{N}$ Engl J Med. 2020;382:e71.

Publisher's Note Springer Nature remains neutral with regard to jurisdictional claims in published maps and institutional affiliations. 